\title{
Reducing the Object Control Skills Gender Gap in Elementary School Boys and Girls
}

\author{
Dwayne P. Sheehan*, Karin Lienhard, Diala Ammar \\ Mount Royal University, Calgary, Canada \\ Email: *dpsheehan@mtroyal.ca, karin.lienhard@ucalgary.ca,dpsheehan@mtroyal.ca
}

How to cite this paper: Sheehan, D. P., Lienhard, K., \& Ammar, D. (2020). Reducing the Object Control Skills Gender Gap in Elementary School Boys and Girls. Advances in Physical Education, 10, 155-168. https://doi.org/10.4236/ape.2020.102014

Received: May 4, 2020

Accepted: May 25, 2020

Published: May 28, 2020

Copyright ( 2020 by author(s) and Scientific Research Publishing Inc. This work is licensed under the Creative Commons Attribution International License (CC BY 4.0).

http://creativecommons.org/licenses/by/4.0/

(c) (i) Open Access

\begin{abstract}
Purpose: This study was aimed to understand the effect of a customized physical education (PE) program on object control skills (OCS) in third grade schoolgirls, and to compare their skills to their male counterparts. Methods: Seventy-six children (32 girls, 44 boys) aged 8 - 9 years were assessed at baseline, after an all-girls six-week intervention program (post-test), and after six weeks of resuming co-educational regular PE (retention). Assessments included the upper limb coordination subtest from the Bruininks-Oseretsky Test of Motor Proficiency, second edition (BOT-2), and the ball skills component of the Test of Gross Motor Development, version three (TGMD-3). Results: Findings from both assessment tools showed that boys had significantly better upper limb coordination and ball skills at baseline $(P<0.05)$, and that this gender gap was no longer significant after the all-girls OCS intervention program. Girls continued to improve their OCS skills, with a total score increase of $+1.3(95 \% \mathrm{CI}=-0.1,2.9)$ for upper limb coordination and $+2.8(P<0.05,95 \% \mathrm{CI}=0.4,5.2)$ for ball skills from baseline to retention. Conclusion: This research suggests that a six-week all-girls intervention program reduces the variance in OCS proficiency in pre-adolescent boys and girls.
\end{abstract}

\section{Keywords}

Object Control, Fundamental Movement Skills, Gender, Intervention

\section{Introduction}

The development of motor competence in children has been identified as a main predictor of physical activity (PA) and sport participation in adolescence and adulthood (Barnett et al., 2008, 2009; Stodden et al., 2008). Motor competence describes human movement as goal-directed or with a purpose (Barnett et al., 
2016), and describes the extent to which one is able to control fundamental movement skills (FMS) (Stodden et al., 2008). FMS are often divided into locomotor and object manipulation skills, also known as object control skills (OCS) or ball skills (Gallahue et al., 2012). OCS involve throwing, dribbling, catching, and kicking/striking a stationary or moving object (Gallahue et al., 2012). OCS are particularly important as they are often highly related to adolescent participation in sport and recreation choices, and are one of the predictors of lifelong involvement in physical activity (Barnett et al., 2009; Loprinzi et al., 2015; Stodden et al., 2008).

Boys are typically more proficient in OCS in childhood and adolescence as compared to girls (Barnett et al., 2010; Berkeley et al., 2001; Bolger, Bolger, O’Neill et al., 2018a; Butterfield et al., 2012; Raudsepp \& Pääsuke, 1995), creating gender differences in FMS development which may influence future participation in recreational activities (Sport for Life for Women and Girls, 2016; Toole \& Kretzschmar, 1993). Because the development of OCS during childhood is an important predictor of PA during adolescence, early awareness of OCS as part of broader FMS programming is critical to promote competence and confidence during childhood and beyond.

Physical literacy including the development of FMS is one of the key goals of physical education ( $\mathrm{PE}$ ), and the quality of PE programming as part of the elementary school curriculum may be a contributor to the development of OCS. Previous research has shown that high-quality PE instruction is critical in the refinement of FMS (Bolger, Bolger, Neill et al., 2018b; Goodway \& Branta, 2003; Stodden et al., 2008). Work in the area of FMS development has shown improved OCS following PE interventions in children (Logan et al., 2012). However, evidence supporting programming that is intentionally designed to increase OCS in girls is missing from the literature, and from resources available to physical educators. There is also very little research measuring the effectiveness of an intervention program aimed at improving OCS with pre-adolescent girls. To the best of our knowledge, there is only one study that has investigated the effect of an all-girl FMS program on ball skills in pre-school girls, aged 3 - 5 years (Veldman et al., 2017). In this study, researchers reported that the intervention group showed a significant gain in ball skills after a nine-week intervention program, and that they were able to maintain this gain up to the retention testing nine weeks post-intervention. However, in this particular study, girls were not compared to their male counterparts.

Many girls chose to drop out of sports during adolescence. It has been suggested that that fundamental movement skills, which include locomotor, manipulative, and balance skills, can be regarded as underlying prerequisites for the engagement in physical activities (Stodden et al., 2008). Increasing FMS among girls could keep more girls in sports. The purpose of this study was to design and evaluate a customized PE program intended to improve OCS in elementary third grade schoolgirls. The OCS program intervention designed as part of this study 
is unique because it is grounded on the principles of the self-determination theory (SDT). The SDT theory (Deci \& Ryan, 2000; Ryan \& Deci, 2000) assumes that humans are inherently proactive, curious, and have a natural love of learning.

SDT has been widely applied to physical education and the understanding of motivation across the lifespan (Fortier et al., 2012; Plotnikoff et al., 2013; Standage \& Ryan, 2012). Specifically, three psychological needs are required for motivation related to physical activity: autonomy (i.e., the choice of action), competence (i.e., feeling confident and effective), and relatedness (i.e., feeling a sense of connection with others) (Fortier et al., 2012; Ryan \& Deci, 2000). These important elements have been emphasized by the teacher facilitating the OCS intervention in this project.

Based on current research, we expected that 1) there would be a significant gender gap in OCS at baseline, with boys achieving higher raw OCS scores than girls, that 2) this gender gap in OCS would be reduced and would no longer be significant after the all-girls six-week intervention program, and that 3) the motor learning effect would be maintained beyond the conclusion of the intervention program as measured by retention testing six weeks after the end of the intervention. Overall, we expected that this all-girl tailored program would reduce the OCS gender gap between pre-adolescent girls and boys.

\section{Methods}

This study used a "pre-post-test" design (Figure 1) to evaluate the change of OCS in third grade school children before and after an intervention (within-subjects design), as well as gender differences comparing girls to boys in the same grade (between-subjects design). OCS were measured at baseline (pre-test), after a

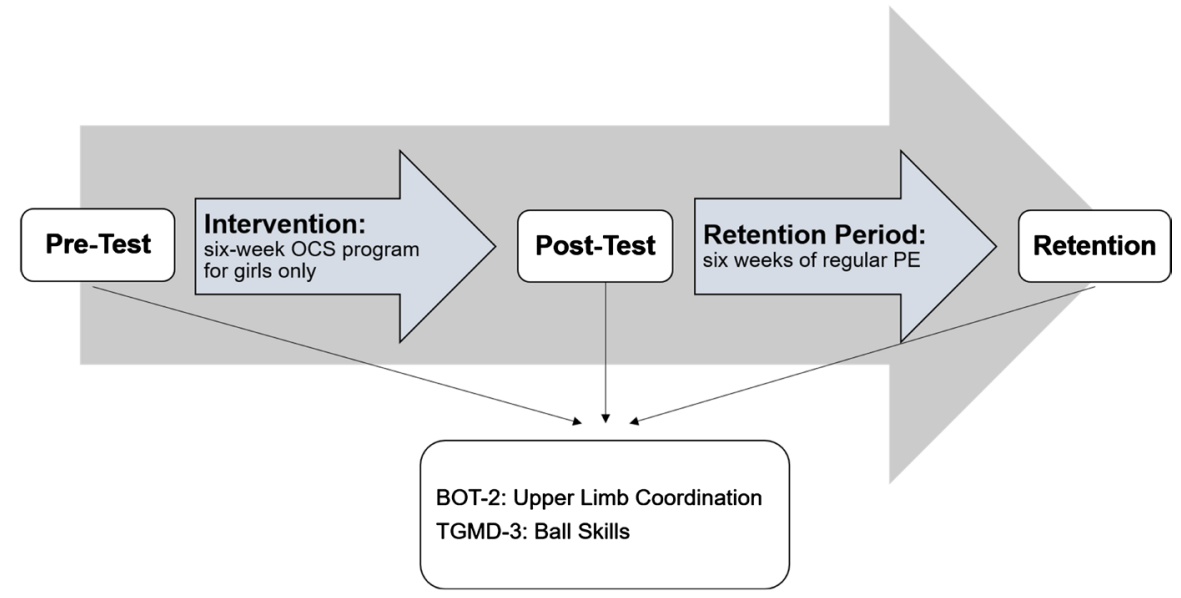

Figure 1. Overview of the study design. OCS for both genders were tested at baseline (pre-test), after the six-week intervention program (post-test), and after a six-week retention period consisting of regular physical education (PE). Assessments included the upper limb coordination subtest from the Bruininks-Oseretsky Test of Motor Proficiency, Second Edition (BOT-2), and the ball skills component of the Test of Gross Motor Development, Version 3 (TGMD-3). 
six-week intervention (post-test), and six weeks after the intervention (retention). The intervention consisted of an all-girls OCS program, guided by a PE specialist.

\section{Participants}

A convenient sample of 76 children $(N=32$ females, $N=44$ males $)$ representing three third-grade classes (ages 8 - 9) agreed to participate in this study. No formal power calculation was conducted. All children were recruited from a publically funded charter school in Calgary, Alberta, Canada. Participants' descriptive data can be found in Table 1 . There were no statistically significant differences $(P>0.05)$ between boys and girls in age, height, weight, and BMI, at pre-test. Ethics approval and informed consent from one parent or guardian of each child and verbal assent from all children were obtained prior to data collection. This study was approved by the Human Research Ethics Board at Mount Royal University.

\section{Instruments}

Weight was measured using a portable children's digital scale (Tanita BF 689) to the nearest 0.1 kilogram and standing height was measured using a portable stadiometer (Seca 213) to the nearest 1.0 centimeter. Participants were asked to take their shoes off for all anthropometric measurements. Body mass index (BMI) was calculated using a commercially available app (BMI Percentile Calculator for Child and Teen, Centers for Disease Control and Prevention, Division of Nutrition, Physical Activity, and Obesity) accounting for the participants' age and gender. OCS were assessed using the subtest for upper limb coordination from the Bruininks-Oseretsky Test of Motor Proficiency, Second Edition (BOT-2) (Bruininks \& Bruininks, 2005), and the ball skills component from the Test of Gross Motor Development, Version 3 (TGMD-3) (Ulrich, 2013). The BOT-2 is a product-oriented assessment tool, whereas the TGMD-3 is a process-oriented (criterion-based) tool. Both assessment tools have been previously validated and are commonly used to determine motor proficiency in children and youth (Webster \& Ulrich, 2017; Wuang \& Su, 2009). We followed the testing procedures as described in the respective manuals (Bruininks \& Bruininks, 2005; Ulrich, 2013).

The Bruininks-Oseretsky Test of Motor Proficiency-Second Edition (BOT-2)

The BOT-2 uses a subset and composite structure that highlights motor

Table 1. Descriptive data of participants at baseline (pre-test), by gender.

\begin{tabular}{|c|c|c|c|}
\hline Measure & Girls $(N=32)$ & Boys $(N=44)$ & Two-Sample T-Test \\
\hline & Mean (SD) & Mean (SD) & $P$-value \\
\hline Age (years) & $8.7(0.4)$ & $8.7(0.3)$ & 0.986 \\
\hline Height $(\mathrm{cm})$ & $131.2(4.0)$ & $132.6(4.8)$ & 0.184 \\
\hline Weight (kg) & $27.9(4.0)$ & $30.0(5.9)$ & 0.099 \\
\hline BMI (Percentile) & $47.0(27.1)$ & $53.4(30.8)$ & 0.354 \\
\hline
\end{tabular}

BMI $=$ Body Mass Index, $\mathrm{SD}=$ Standard Deviation. 
performance in the broad functional areas of stability, mobility, strength, coordination, and object manipulation. It consists of a gross and fine motor composite; gross motor composite involves subtests for bilateral coordination, balance, running speed and agility, and strength; fine motor composite includes subtests for fine motor precision, fine motor integration, manual dexterity, and upper-limb coordination. In order to evaluate OCS for the present study, only the test protocol for the upper limb coordination subtest was conducted.

The upper limb coordination protocol consists of the following seven tasks (Bruininks \& Bruininks, 2005):

1) Dropping and catching the ball with both hands;

2) Catching the ball with both hands from a ten feet distance;

3) Dropping and catching the ball with one hand;

4) Catching the ball from a ten feet distance with one hand;

5) Dribbling the ball with one hand;

6) Dribbling the ball with alternating hands; and

7) Throwing a ball at a target.

The raw scores were converted to numerical point scores ranging from 0 to 35, and a total point score was reported.

\section{The Test of Gross Motor Development-Version 3 (TGMD-3)}

The TGMD-3 assesses thirteen fundamental motor skills, divided into two subscales, i.e., locomotor and ball skills (Ulrich, 2013; Webster \& Ulrich, 2017). Only the seven test items for the ball skills were conducted as part of this study, which included two-handed and one-handed striking, dribbling, overhand throwing, underhand throwing, catching, and kicking. Each student performed the seven test items across two trials that were each scored based on three to five specific performance criteria depending on the testing item, with a total score of 54. The researcher demonstrated the proper execution of the skill, and participants were then asked to complete one practice and then two formal trials. Both formal trials were rated and coded by two researchers in live-time, according to the guidelines outlined in Webster and Ulrich (Webster \& Ulrich, 2017). Researchers were trained using the TGMD-3 training protocols prior to the commencement of data collection on the TGMD-3 guidelines and scoring protocol by the Principal Investigator. Inter-rater reliability was consistently greater than $80 \%$.

\section{Procedures}

Participants were evaluated individually by two trained research assistants. The testing area was a dedicated space in the participants' school, and tests were conducted throughout the day. Children moved through the subtests in random order of availability. The order of testing remained the same for each participant when they returned for post- and retention testing. The assessment of each individual took approximately 20 minutes. Anthropometric measurements were collected prior to the start of the assessment. Pre-test, post-test, and retention were identical procedures. 


\section{Intervention}

The intervention occurred daily, as part of the regular school PE programming that the children would take normally. During the research intervention period, co-ed classes that occurred at the same time were combined and then separated by gender. The boys continued to receive the regular PE content as scheduled by the school, whereas the girls received customized OCS instruction (Garet et al., 2001). The six-week OCS PE program was developed in collaboration with an elementary school PE specialist based on the government approved curriculum criteria expected for this grade level. Girls are not normally separated from boys during PE at this grade, but arrangements were made with the school to allow this alternative delivery method for this research. The girls participated in a customized OCS unit of instruction, which consisted of 27 classes spread over a period of six weeks as part of the daily PE programming in the school. Each class was 35 minutes in length and took place in half of the school gymnasium (separated by a retractable wall) while the boys participated in the other half. The boys continued with the normally scheduled activities in their PE class such as floor hockey, basketball, and fitness activities taught by an equally qualified PE specialist teacher.

As previously described, the PE intervention program was based on the theoretical principles of the SDT (Deci \& Ryan, 2000; Ryan \& Deci, 2000). The intervention design for this study was developed based on the three basic psychological needs that align with SDT: autonomy (i.e., the choice of action), competence (i.e., feeling confident and effective), and relatedness (i.e., feeling a sense of connection with others) (Fortier et al., 2012; Ryan \& Deci, 2000). Examples of how SDT was embedded in the intervention included: providing participants with choice of equipment, allowing participants to form groups with friends, and providing variation in the tasks by modifying the equipment or expected outcomes. Details on the PE intervention program can be found in Table 2.

\section{Statistical Analysis}

All statistical procedures were performed using Stata S/E Version 13 software (StataCorp. 2013. Stata Statistical Software: Release 13. College Station, TX: StataCorp LP.). Normal distribution of the data was determined using both visual methods (box plots and Q-Q plots) and formal numeric methods (Shapiro Wilk test), which provided evidence of a normal distribution $(P>0.05)$. Descriptive statistics (mean and standard deviation) were calculated by gender for age, height, weight, and BMI, and were compared between boys and girls using two-sample T-tests. In order to determine OCS, mean values and standard deviations (SD) were calculated for the TGMD-3 ball skills composite and BOT-2 upper limb coordination total point scores for boys and girls separately, and for all time points. There was no adjustment for age and gender; only raw scores were used to compare the boys' and girls' results. Two mixed effects linear models were developed to examine the relationship between gender and OCS: one model for BOT-2 and one model for TGMD-3. The fixed effects were gender 
Table 2. Overview of the customized object control skills (OCS) physical education intervention program.

Week 1 (first 3 PE classes): Emphasis on throwing, catching, and dribbling using modified games, individual challenges, partner challenges, group challenges, and a variety of equipment choice.

Day 1: Building the learning environment with a variety of OCS equipment (e.g., basketballs, soccer balls, batting tees with bat, tennis racquets, table tennis racquets, juggling balls, and plate spinning).

Day 2: Continued exploration of OCS using gator balls, soccer balls, batting tee, tennis racquets, badminton racquets, or table tennis racquets to knock over previously built targets.

Day 3: Long term group team building utilizing OCS equipment to complete group challenges including passes between each group member with a variety of balls.

Week 2 (next 4 PE classes): Continuing throwing and catching emphasis using circus arts equipment and juggling skills (e.g., plate juggling, diabolo juggling, devil stick juggling, ball juggling, club juggling, and bean bag juggling).

Day 4: Focus on underhand throwing and catching with a variety of balls by moving in a circle and passing a variety of balls around the circle.

Day 5: Focus on review of underhand throwing and adding overhand throwing and catching.

Day6: Focus on throwing and catching utilizing circus arts equipment.

Day7: Continued focus on throwing and catching utilizing circus arts equipment.

Week 3 (7 PE classes): Emphasis on striking using tennis, badminton and baseball modified games, individual challenges, partner challenges, group challenges, and a variety of equipment choices.

Day 8: Exploration, individual practice, and individual challenges with a variety of striking equipment (e.g., tennis racquets, table tennis racquets, badminton racquets, and baseball bats).

Day9: Exploration with badminton racquets striking individually and with a partner.

Day 10: Exploration with tennis racquets individually and with a partner.

Day 11: Tennis racquet challenges with partners and long term groups using the tennis nets.

Day 12: Exploration with table tennis racquets individually and with a partner.

Day 13: Table tennis racquet with table tennis table.

Day 14: Baseball batting-batting game towards the wall.

Week 4 (4 PE classes): Kicking and footwork emphasis using modified games, individual challenges, partner challenges, group challenges, and a variety of equipment choice (e.g., hacky sacs and modified soccer balls).

Day 15: Feet only day exploration, individual practice, and individual challenge-day with hacky sacs (gripper soccer balls and/or gator balls as other options for student choice).

Day 16: Soccer ball and hacky sac review by kicking game towards the wall and dribbling and kicking at targets.

Day 17: Basketball dribbling and tennis ball dribbling practice and challenges.

Day 18: Combining hand dribbling and foot dribbling.

Week 5 (4 PE classes): Station challenges utilizing all object manipulation skills (i.e., throwing, catching, dribbling, striking, and kicking).

Day 19: Introduction to spike ball to utilize OCS and throwing and catching skills.

Day 20: Spike ball continued (2 vs. 2 practice).

Day21: Stations: tennis, badminton, table tennis, circus arts (with hacky sac and soccer balls), spike ball, and baseball.

Day 22: Stations: tennis, badminton, table tennis, circus arts (with hacky sac and soccer balls), spike ball, baseball—continued from Day \#21.

Week 6 (5 PE classes): Obstacle course challenges utilizing all object manipulation skills.

Day 23: Teacher-created obstacle course utilizing throwing and striking at targets.

Day 24 and 25: Student created obstacle courses.

Day 26 and 27: Game day celebration utilizing all OCS.

and time point (pre-test, post-test, retention), and these two variables were included as an interaction effect in the model in order to examine gender differ- 
ences in OCS over time. To allow for individual variation in responses, the participant was included in the model as a random effect. Post-hoc pairwise comparisons were conducted to examine changes within each group over time, and adjusted $P$-values using the Sidak method are reported for all comparisons. The level of significance was set at $\alpha=0.05$.

\section{Results}

\section{BOT-2 Upper limb coordination}

Between-gender comparisons showed that boys had a significantly higher average score than girls at the pre-test in BOT-2 upper limb coordination $(P=$ 0.040). Following the intervention, gender discrepancy was no longer significant for the BOT-2 upper limb coordination subtest at post-intervention $(P=0.397)$ and retention $(P=0.740)$. Girls improved, albeit not significantly, their scores by an average $+0.3(95 \% \mathrm{CI}=-1.1,1.8)$ from pre-test to post-test and by an average of $+1.0(95 \% \mathrm{CI}=-0.8,2.8)$ from post-test to retention, closing the gap with their male counterparts (Figure 2, Table 3 ).

Table 3. Outcomes for the Bruininks-Oseretsky Test of Motor Proficiency, Second Edition (BOT-2) and the Test of Gross Motor Development, Version 3 (TGMD-3): between and within group difference for girls $(N=32)$ and boys $(N=44)$ across pre-test, post-test, and retention time points.

\begin{tabular}{|c|c|c|c|}
\hline Between Group Differences & $\begin{array}{c}\text { Pre-test } \\
\text { Average Score (SD) }\end{array}$ & $\begin{array}{c}\text { Post-test } \\
\text { Average Score (SD) }\end{array}$ & $\begin{array}{c}\text { Retention } \\
\text { Average Score (SD) }\end{array}$ \\
\hline Girls & $29.1(5.6)$ & $29.4(4.4)$ & $30.4(4.0)$ \\
\hline Boys & $31.6(3.9)$ & $30.9(4.7)$ & $31.4(4.3)$ \\
\hline Difference $(95 \% \mathrm{CI})$ & $2.5(0.1,5.1)$ & $1.5(-1.0,4.0)$ & $1.0(-1.5,3.4)$ \\
\hline Sidak adjusted p-value & 0.040 & 0.397 & 0.740 \\
\hline${ }^{*}$ Within Group Differences & $\begin{array}{l}\text { Pre-test to Post-test } \\
\text { Average Change }(95 \% \mathrm{CI})\end{array}$ & $\begin{array}{c}\text { Post-test to Retention } \\
\text { Average Change (95\% CI) }\end{array}$ & $\begin{array}{c}\text { Pre-test to Retention } \\
\text { Average Change ( } 95 \% \mathrm{CI})\end{array}$ \\
\hline Girls & $0.3(-1.1,1.8)$ & $1.0(-0.8,2.8)$ & $1.3(-0.1,2.9)$ \\
\hline Boys & $-0.7(-2.0,0.5)$ & $0.5(-1.0,2.0)$ & $-0.2(-1.5,1.0)$ \\
\hline \multicolumn{4}{|c|}{ TGMD-3: Ball Skills (scoring range: 0 - 54) } \\
\hline Between Group Differences & $\begin{array}{c}\text { Pre-test } \\
\text { Average Score (SD) }\end{array}$ & $\begin{array}{c}\text { Post-test } \\
\text { Average Score (SD) }\end{array}$ & $\begin{array}{c}\text { Retention } \\
\text { Average Score (SD) }\end{array}$ \\
\hline Girls & $38.3(4.9)$ & $39.7(6.1)$ & $41.1(4.3)$ \\
\hline Boys & $43.8(5.3)$ & $42.4(6.0)$ & $44.8(5.7)$ \\
\hline Difference $(95 \% \mathrm{CI})$ & $5.5(2.4,8.5)$ & $2.7(-0.3,5.7)$ & $3.7(0.7,6.8)$ \\
\hline Sidak adjusted p-value & $<0.001$ & 0.098 & 0.010 \\
\hline${ }^{*}$ Within Group Differences & $\begin{array}{l}\text { Pre-test to Post-test } \\
\text { Average Change }(95 \% \mathrm{CI})\end{array}$ & $\begin{array}{c}\text { Post-test to Retention } \\
\text { Average Change (95\% CI) }\end{array}$ & $\begin{array}{c}\text { Pre-test to Retention } \\
\text { Average Change (95\% CI) }\end{array}$ \\
\hline Girls & $1.4(-1.0,3.8)$ & $1.4(-1.4,4.2)$ & $2.8(0.4,5.2)^{\star * *}$ \\
\hline Boys & $-1.4(-3.5,0.6)$ & $2.4(0.1,4.9)^{\star \star}$ & $1.0(-1.0,3.1)$ \\
\hline
\end{tabular}

${ }^{*}$ All Sidak adjusted $P$-values $>0.05$ for BOT-2 within group comparisons; ${ }^{*}$ Sidak adjusted $P$-value $=0.048$; ${ }^{* *}$ Sidak adjusted $P$-value $=0.016$. 


\section{TGMD-3 ball skills}

Similar results were observed for the TGMD-3 ball skill test (Figure 2, Table 3 ): boys had a significantly higher average score at pre-test compared to girls ( $P$ $<0.001)$, however, girls significantly $(P=0.016)$ improved their scores by an average of $+2.8(95 \% \mathrm{CI}=0.4,5.2)$ from pre-test to retention, and showed non-significant increases of $+1.495 \% \mathrm{CI}=-1.0,3.8)$ from pre-test to post-test and $+1.4(95 \% \mathrm{CI}=-1.4,4.2)$ from post-test to retention. Boys significantly $(P<$ $0.048)$ improved their TGMD-3 ball skill scores by an average of $+2.4(95 \% \mathrm{CI}=$ $0.1,4.9)$ from post-test to retention. Although the girls improved their ball skills throughout the study, they still scored significantly lower TGMD-3 ball skill scores, on average, than their male counterparts at the retention time point ( $P=$ $0.010)$.

\section{Discussion}

The purpose of this study was to investigate the effect of an all-girls intervention program on pre-adolescent gender gap in OCS. Boys' and girls' OCS skills were tested using the BOT-2 subtest for upper limb coordination and the TGMD-3 ball skills component, measured at baseline, after a six-week intervention program (post-test), and after a six-week period of regular PE (retention). This study found that boys had significantly better upper limb coordination and ball skills at baseline which confirmed our first hypothesis. This gender difference was reduced at post-test and was no longer statistically significant after the all-girls OCS intervention program, which confirmed our second hypothesis. After completion of the intervention program, girls continued to improve their OCS skills, with a total score increase (from baseline to retention) of +1.3 for upper limb coordination and $+2.8(P<0.05)$ for ball skills from baseline to

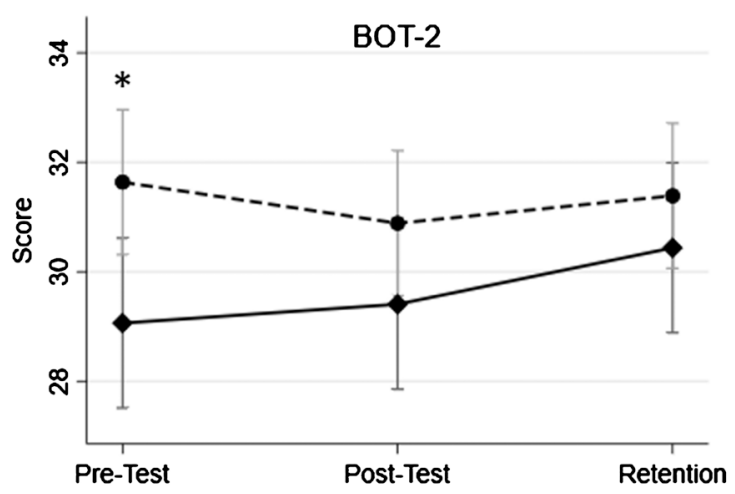

Pre-Test

Post-Test

Retention

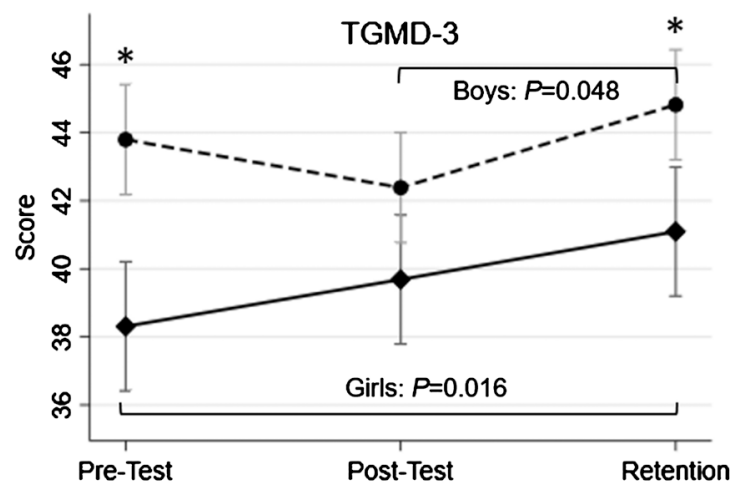

Female ---- Male

Figure 2. Changes in the Bruininks-Oseretsky Test of Motor Proficiency, Second Edition (BOT-2) upper limb coordination total point scores (mean and 95\% CI, left graph) and changes in the Test of Gross Motor Development, Version 3 (TGMD-3) ball skill scores (mean and 95\% CI, right graph) across time points by gender (boys $N=44$, girls $N=32)$. Girls significantly increased their TGMD-3 score from pre-test to retention $(P=0.016)$, boys significantly increased their TGMD-3 score from post-test to retention $(P=0.048)$. ${ }^{\star}$ Boys $>$ girls at pre-test $(P<$ 0.05). 
retention, partially confirming our third hypothesis. The gender difference at retention was again statistically significant, however, the average difference between the boys and girls was reduced.

To the best of our knowledge, this was the first study to examine the effects of an all-girls OCS intervention program in elementary school girls. The impact of these results can influence the perception of caregivers and teachers regarding the instructional design of all FMS. Specifically, primary school teachers in kindergarten and first grade should recognize that there may be a difference in OCS based on the varying experiences that children have had at home prior to starting school. However, elementary school (K-6) PE teachers can serve as an equalizing influence and should support girls who may have started to fall behind in OCS. This can be done by recognizing the gender discrepancy and intentionally designing activities that focus on the OCS. Based on the author's experience as an elementary PE teacher, we believe that the transition from skill development to game play happens too early and is often based on the progress of the highest achieving boys in the class.

A previous study found similar results in terms of retention effects of an FMS intervention on ball skills in pre-school girls (Veldman et al., 2017). They reported a significant gain in ball skills after a nine-week intervention program, which was maintained during a nine-week retention period. While the present study found that gender variance in OCS was reduced after a six-week intervention program, a longer intervention period may have further improved the girls' OCS. Future research should focus on FMS intervention programs lasting between six and nine weeks (Sefton et al., 2011). Alternatively, subsequent research may investigate strategies to incorporate OCS development while children participate in warm-up locomotor activities at the start of each PE class.

The results of this project support the premise that if provided the same opportunities, pre-adolescent girls should be at or near their male peers in FMS (Breslin et al., 2012). With no apparent physiological advantage of boys over girls prior to the adolescent growth spurt, the reason for the gender gap in OCS is likely environmental and societal; boys and girls may experience PA and sport opportunities in different ways. We hypothesize that if girls were afforded similar robust and rugged PA opportunities, they would develop all FMS (including OCS) equally. Previous literature suggests that the differences in OCS could be attributed to different social gender roles afforded to boys and girls (Breslin et al., 2012). For example, boys may have more opportunities than girls to engage in physical activities that promote OCS. This project confirms that given intentional and age appropriate remediation using the SDT framework, girls can begin to close the OCS gender gap.

The adolescent growth spurt and other factors related to puberty may influence variance in OCS between boys and girls (Bisi \& Stagni, 2016). While every effort was made to avoid recruiting children who were experiencing a growth spurt, there may have been early developing children in this group of partici- 
pants, which may pose a limitation to the study. Previous research has reported that FMS can drop after experiencing a major growth spurt (Bisi \& Stagni, 2016; Sheehan \& Lienhard, 2018), and that girls typically experience their growth spurt at a younger age than boys (Frisch \& Revelle, 1971).

Further limitations of this study include a relatively small sample size $(N=32$ females; $N=44$ males), as well as the absence of a randomized controlled group. Future studies are advised to investigate the effect of an all-girl OCS program using a larger sample size, including a control group consisting of randomly selected girls who continue the regular PE program. Furthermore, future research should investigate whether a mixed gender OCS program has the same impact on reducing the gender gap (Robinson \& Goodway, 2009). The intervention period may also be extended beyond six weeks or be implemented over a series of smaller time periods. Alternative methods of delivering OCS such as a specialized warm-ups or lunchtime intramurals could also be considered in future OCS intervention programs.

Perceived competence of FMS may play a role in physical activity participation in elementary school-aged girls (Khodaverdi et al., 2013). It is unclear whether perceived FMS influenced the girls' OCS skills as this was not assessed as part of this study. However, children taught by PE specialists trained in teaching FMS show higher levels of perceived competence than those taught by instructors with no such training (Breslin et al., 2012). It can therefore be assumed that perceived FMS would be positively affected by an OCS intervention program, which may affect girls' physical activity involvement in later years. Future research should confirm this hypothesis, as this may have implications on the structure of school-children's PE curriculum.

A strength of the current study is the development of the customized girls-only OCS intervention program by the school PE specialist. Each lesson was designed with the SDT elements in mind, promoting participation in PA based on the basic psychological needs.

The findings of this study reinforce the importance of creating, implementing, and evaluating FMS programs that are relevant and developmentally appropriate. Effective instruction in summer camps, school, recreation programming, and sport teams must consider both genders, age, and cultural sensitivity in order to maximize the potential of all children. Greater parental awareness that PA at home should be inclusive and supportive of young girls can help foster a sense of inclusion and lead to greater competence and confidence (Clark, 2005; Goodway \& Branta, 2003; Robinson \& Goodway, 2009; Valentini \& Rudisill, 2004). This increased self-concept may lead to more PA participation and an active healthy lifestyle across the lifespan.

\section{Conclusion}

This research has demonstrated that it is possible to reduce the variance in OCS motor proficiency in pre-adolescent boys and girls with an intentionally de- 
signed program based on the principles of the SDT. The intervention in this project focused on girls learning in a homogeneous gender-friendly environment and used instructional strategies and teaching tactics that were supported by evidence. $\mathrm{PE}$ teachers should examine the present intervention and make an intentional effort to focus on OCS development in pre-adolescent girls, as FMS in childhood has been linked to lifelong participation in PA. Practical implications include creating more OCS interventions for girls that would lead to stronger FMS and in turn higher participation in sports and physical activity.

\section{Conflicts of Interest}

The authors declare no conflicts of interest regarding the publication of this paper.

\section{References}

(2016). Sport for Life for Women and Girls. http://canadiansportforlife.ca/sport-life-women-and-girls

Barnett, L. M., Beurden, E. V., Morgan, P. J., Brooks, L. O., \& Beard, J. R. (2008). Does Childhood Motor Skill Proficiency Predict Adolescent Fitness? Medicine \& Science in Sports \& Exercise, 40, 2137-2144. https://doi.org/10.1249/MSS.0b013e31818160d3

Barnett, L. M., van Beurden, E., Morgan, P. J., Brooks, L. O., \& Beard, J. R. (2009). Childhood Motor Skill Proficiency as a Predictor of Adolescent Physical Activity. Journal of Adolescent Health, 44, 252-259. https://doi.org/10.1016/j.jadohealth.2008.07.004

Barnett, L. M., Lai, S. K., Veldman, S. L. C., Hardy, L. L., Cliff, D. P., Morgan, P. J., Zask, A., Lubans, D. R., Shultz, S. P., Ridgers, N. D., Rush, E., Brown, H. L., \& Okely, A. D. (2016). Correlates of Gross Motor Competence in Children and Adolescents: A Systematic Review and Meta-Analysis. Sports Medicine, 46, 1663-1688.

https://doi.org/10.1007/s40279-016-0495-z

Barnett, L. M., van Beurden, E., Morgan, P. J., Brooks, L. O., \& Beard, J. R. (2010). Gender Differences in Motor Skill Proficiency from Childhood to Adolescence: A Longitudinal Study. Research Quarterly for Exercise and Sport, 81, 162-170. https://doi.org/10.1080/02701367.2010.10599663

Berkeley, S. L., Zittel, L. L., Pitney, L. V., \& Nichols, S. E. (2001). Locomotor and Object Control Skills of Children Diagnosed with Autism. Adapted Physical Activity Quarterly, 18, 405-416. https://doi.org/10.1123/apaq.18.4.405

Bisi, M. C., \& Stagni, R. (2016). Development of Gait Motor Control: What Happens after a Sudden Increase in Height during Adolescence? BioMedical Engineering Online, 15, Article No. 47. https://doi.org/10.1186/s12938-016-0159-0

Bolger, L. E., Bolger, L. A., Neill, C. O., Coughlan, E., O’Brien, W., Lacey, S., \& Burns, C. (2018a). The Effectiveness of Two Interventions on Fundamental Movement Skill Proficiency among a Cohort of Irish Primary School Children. Journal of Motor Learning and Development, 7, 153-179.

Bolger, L. E., Bolger, L. A., O’Neill, C., Coughlan, E., O’Brien, W., Lacey, S., \& Burns, C. (2018b). Age and Sex Differences in Fundamental Movement Skills among a Cohort of Irish School Children. Journal of Motor Learning and Development, 6, 81-100. https://doi.org/10.1123/jmld.2017-0003

Breslin, G., Murphy, M., McKee, D., Delaney, B., \& Dempster, M. (2012). The Effect of Teachers Trained in a Fundamental Movement Skills Programme on Children's 
Self-Perceptions and Motor Competence. European Physical Education Review, 18, 114-126. https://doi.org/10.1177/1356336X11430657

Bruininks, R., \& Bruininks, B. (2005). Bruininks-Oseretsky Test of Motor Proficiency (BOT-2) (2nd ed.). https://doi.org/10.1037/t14991-000

Butterfield, S. A., Angell, R. M., \& Mason, C. A. (2012). Age and Sex Differences in Object Control Skills by Children Ages 5 to 14. Perceptual and Motor Skills, 114, 261-274. https://doi.org/10.2466/10.11.25.PMS.114.1.261-274

Clark, J. E. (2005). From the Beginning: A Developmental Perspective on Movement and Mobility. Quest, 57, 37-45. https://doi.org/10.1080/00336297.2005.10491841

Deci, E. L., \& Ryan, R. M. (2000). The "What" and "Why" of Goal Pursuits: Human Needs and the Self-Determination of Behavior. Psychological Inquiry, 11, 227-268. https://doi.org/10.1207/S15327965PLI1104_01

Fortier, M. S., Duda, J. L., Guerin, E., \& Teixeira, P. J. (2012). Promoting Physical Activity: Development and Testing of Self-Determination Theory-Based Interventions. International Journal of Behavioral Nutrition and Physical Activity, 9, 20. https://doi.org/10.1186/1479-5868-9-20

Frisch, R. E., \& Revelle, R. (1971). The Height and Weight of Girls and Boys at the Time of Initiation of the Adolescent Growth Spurt in Height and Weight and the Relationship to Menarche. Human Biology, 43, 140-159.

Gallahue, D. L., Ozmun, J. C., \& Goodway, J. (2012). Understanding Motor Development: Infants, Children, Adolescents and Adults (7th ed.). New York, London: McGraw-Hill. https://trove.nla.gov.au/work/11623306

Garet, M. S., Porter, A. C., Desimone, L., Birman, B. F., \& Yoon, K. S. (2001). What Makes Professional Development Effective? Results from a National Sample of Teachers. American Educational Research Journal, 38, 915-945. https://doi.org/10.3102/00028312038004915

Goodway, J. D., \& Branta, C. F. (2003). Influence of a Motor Skill Intervention on Fundamental Motor Skill Development of Disadvantaged Preschool Children. Research Quarterly for Exercise and Sport, 74, 36-46. https://doi.org/10.1080/02701367.2003.10609062

Khodaverdi, Z., Bahram, A., Khalaji, H., \& Kazemnejad, A. (2013). Motor Skill Competence and Perceived Motor Competence: Which Best Predicts Physical Activity among Girls? Iranian Journal of Public Health, 42, 1145-1150.

Logan, S. W., Robinson, L. E., Wilson, A. E., \& Lucas, W. A. (2012). Getting the Fundamentals of Movement: A Meta-Analysis of the Effectiveness of Motor Skill Interventions in Children: Effectiveness of Motor Skill Interventions. Child: Care, Health and Development, 38, 305-315. https://doi.org/10.1111/j.1365-2214.2011.01307.x

Loprinzi, P. D., Davis, R. E., \& Fu, Y.-C. (2015). Early Motor Skill Competence as a Mediator of Child and Adult Physical Activity. Preventive Medicine Reports, 2, 833-838. https://doi.org/10.1016/j.pmedr.2015.09.015

Plotnikoff, R. C., Costigan, S. A., Karunamuni, N., \& Lubans, D. R. (2013). Social Cognitive Theories Used to Explain Physical Activity Behavior in Adolescents: A Systematic Review and Meta-Analysis. Preventive Medicine, 56, 245-253. https://doi.org/10.1016/j.ypmed.2013.01.013

Raudsepp, L., \& Pääsuke, M. (1995). Gender Differences in Fundamental Movement Patterns, Motor Performances, and Strength Measurements of Prepubertal Children. Pediatric Exercise Science, 7, 294-304. https://doi.org/10.1123/pes.7.3.294

Robinson, L. E., \& Goodway, J. D. (2009). Instructional Climates in Preschool Children 
Who Are At-Risk. Part I: Object-Control Skill Development. Research Quarterly for Exercise \& Sport, 80, 533-542. https://doi.org/10.5641/027013609X13088500159480

Ryan, R. M., \& Deci, E. L. (2000). Self-Determination Theory and the Facilitation of Intrinsic Motivation, Social Development, and Well-Being. The American Psychologist, 55, 68-78. https://doi.org/10.1037/0003-066X.55.1.68

Sefton, J. M., Yarar, C., Hicks-Little, C. A., Berry, J. W., \& Cordova, M. L. (2011). Six Weeks of Balance Training Improves Sensorimotor Function in Individuals with Chronic Ankle Instability. The Journal of Orthopaedic and Sports Physical Therapy, 41, 81-89. https://doi.org/10.2519/jospt.2011.3365

Sheehan, D. P., \& Lienhard, K. (2018). Gross Motor Competence and Peak Height Velocity in 10- to 14-Year-Old Canadian Youth: A Longitudinal Study. Measurement in Physical Education and Exercise Science, 23, 89-98. https://doi.org/10.1080/1091367X.2018.1525385

Standage, M., \& Ryan, R. M. (2012). Self-Determination Theory and Exercise Motivation: Facilitating Self-Regulatory Processes to Support and Maintain Health and Well-Being. In Advances in Motivation in Sport and Exercise (3rd ed., pp. 233-270). Champaign, IL: Human Kinetics. https://doi.org/10.5040/9781492595182.ch-007

Stodden, D. F., Goodway, J. D., Langendorfer, S. J., Roberton, M. A., Rudisill, M. E., Garcia, C., \& Garcia, L. E. (2008). A Developmental Perspective on the Role of Motor Skill Competence in Physical Activity: An Emergent Relationship. Quest, 60, 290-306. https://doi.org/10.1080/00336297.2008.10483582

Toole, T., \& Kretzschmar, J. C. (1993). Gender Differences in Motor Performance in Early Childhood and Later Adulthood. Women in Sport and Physical Activity Journal, 2, 41-71. https://doi.org/10.1123/wspaj.2.1.41

Ulrich, D. A. (2013). The Test of Gross Motor Development-3 (TGMD-3): Administration, Scoring, \& International Norms. Spor Bilimleri Dergisi, 24, 27-33.

Valentini, N. C., \& Rudisill, M. E. (2004). An Inclusive Mastery Climate Intervention and the Motor Skill Development of Children with and without Disabilities. Adapted Physical Activity Quarterly, 21, 330-347. https://doi.org/10.1123/apaq.21.4.330

Veldman, S. L. C., Palmer, K. K., Okely, A. D., \& Robinson, L. E. (2017). Promoting Ball Skills in Preschool-Age Girls. Journal of Science and Medicine in Sport, 20, 50-54. https://doi.org/10.1016/j.jsams.2016.04.009

Webster, E. K., \& Ulrich, D. A. (2017). Evaluation of the Psychometric Properties of the Test of Gross Motor Development-Third Edition. Journal of Motor Learning and Development, 5, 45-58. https://doi.org/10.1123/jmld.2016-0003

Wuang, Y.-P., \& Su, C.-Y. (2009). Reliability and Responsiveness of the Bruininks-Oseretsky Test of Motor Proficiency-Second Edition in Children with Intellectual Disability. Research in Developmental Disabilities, 30, 847-855.

https://doi.org/10.1016/j.ridd.2008.12.002 